\title{
AVALIAGÃ̃ DO IMPACTO REGULATÓRIO E SUA DIFUSÃO NO CONTEXTO BRASILEIRO
}

\author{
REGULATORY IMPACT ASSESSMENT AND ITS PROPAGATION WITHIN THE BRAZILIAN CONTEXT \\ MANIFESTACIÓN DE IMPACTO REGULATORIO Y SU DIFUSIÓN EN EL CONTEXTO BRASILEÑO
}

\section{RESUMO}

A Avaliação do Impacto Regulatório (AIR) é um dos instrumentos que visam melhorar a qualidade de regulação. Pesquisas destacam limitações no processo de adoção da AIR em países em desenvolvimento, devido à influência de variáveis políticas que operam no contexto nacional ou à escassez de capacidades organizacionais. Este estudo avalia como variáveis políticas e organizacionais influenciam a difusão da AIR no Brasil. Para isso, foi realizada uma pesquisa de campo qualitativa, por meio de entrevistas semiestruturadas com atores do modelo regulatório, focando na familiaridade com o instrumento, nas capacidades organizacionais existentes, no contexto burocrático, no processo de políticas públicas e na posição dos principais atores do marco regulatório brasileiro sobre AIR. Essa pesquisa mostra a relevância das capacidades organizacionais, assim como a influência dos fatores políticos no processo de difusão da AIR. Esses últimos explicam a resistência perante os modelos organizacionais de supervisão regulatória, necessários para a adoção da AIR.

PALAVRAS-CHAVE Avaliação do impacto regulatório, difusão, Organização para a Cooperação e Desenvolvimento Econômico (OCDE), governo federal, controle.

Alketa Peci alketa@fgv.br

Professora da Escola Brasileira de Administração Pública e de Empresas, Fundação Getulio Vargas - Rio de Janeiro - RJ, Brasil

Abstract Regulatory ImpactAssessment (RIA) is one of the instruments aiming regulatory quality improvement. Research has shown limitations in RIA diffusion process, particularly in developing countries, due to political forces at work in domestic contexts or to the available organizational capacities. This paper evaluates how contextual variables, specifically political and organizational ones, influence RIA diffusion in Brazil. The paper is based on field research consisting of semi-structured interviews with the stakeholders of the Brazilian regulatory framework, which analyzed RIA concept familiarity among stakeholders, available organizational capacities, bureaucratic context, policy process, and pivotal stakeholders' standpoint in adopting RIA. This research reveals the relevance of organizational capacities, as well as the influence of political variables in RIA diffusion process. Political variables explain the resistance toward oversight regulatory bodies, necessaries for implementing RIA. keywords Regulatory impact assessment, diffusion, OECD (Organization for Economic Co-operation and Development), federal government, control.

Resumen La Manifestación de Impacto Regulatorio (MIR) es un de los instrumentos que visan mejorar la calidad de regulación. Investigaciones destacan limitaciones en el proceso de adopción de la MIR en países en desarrollo, debido a la influencia de variables políticas que operan en el contexto nacional o a la escasez de capacidades organizacionales. Este estudio evalúa como variables políticas y organizacionales influencian la difusión de la MIR en el Brasil. Para eso, se realizó una investigación de campo cualitativa, por medio de entrevistas semi-estructuradas con atores del modelo regulatorio, centrándose en la familiaridad con el instrumento, en las capacidades organizacionales existentes, en el contexto burocrático, en el proceso de políticas públicas y en la posición de los principales actores del marco regulatorio brasileño sobre MIR. Esa investigación demuestra la relevancia de las capacidades organizacionales, así como la influencia de los factores politicos en el proceso de difusión de la MIR. Eses últimos explican la resistencia delante de los modelos organizacionales de supervisión regulatoria, necesarios para la adopción de la MIR.

Palabras clave Manifestación de impacto regulatorio, difusión, Organización para la Cooperación y el Desarrollo Económico (OCDE), gobierno federal, control. 


\section{INTRODUÇÃO}

A regulação entra na agenda política brasileira como consequência de um processo de desestatização que privilegiou as estratégias de privatização e concessão de serviços públicos, mas foi caracterizado por relativa fragmentação das políticas regulatórias e pela priorização dos objetivos econômicos. Embora a regulação represente uma importante inovação institucional, os dilemas regulatórios ainda persistem num contexto de esvaziamento do processo de formulação de políticas públicas, heterogeneidade de modelos institucionais e organizacionais e complexidade de instrumentos regulatórios que tornam mais evidente a necessidade de coordenação intragovernamental e de melhoria da qualidade regulatória (OCDE, 2008a; PECI, 2007; SANTOS, 2009).

Entre os instrumentos internacionalmente adotados com o objetivo de melhorar a qualidade regulatória, destaca-se a Avaliação de Impacto Regulatório (AIR), recentemente recomendada no relatório Brasil: fortalecendo a governança pelo crescimento, produzido pela Organização para Cooperação e Desenvolvimento Econômico (OCDE, 2008a). O governo federal, por intermédio da Casa Civil da Presidência da República e seu Programa de Fortalecimento da Capacidade Institucional para Gestão em Regulação (PRO-REG), encomendou uma série de estudos que buscavam analisar as condições institucionais e organizacionais, assim como estratégias de adoção da AIR e do órgão de supervisão da qualidade regulatória no nível federal.

Entretanto, pesquisas demonstram que a difusão da AIR em vários países do mundo não tem se traduzido em convergência nas práticas e nas formas de utilização do instrumento. Para Radaelli (2005, 2007), essa falta de convergência explica-se pelas variáveis de natureza política presentes no contexto doméstico de adoção, tais como natureza da burocracia e do processo político, ou posições dos principais atores envolvidos no processo regulatório. Por outro lado, pesquisas sobre adoção da AIR em países em desenvolvimento atribuem essa falta de convergência à falta de capacidades organizacionais, tais como dados e sistemas de informações precárias, recursos humanos pouco treinados ou estruturas organizacionais inadequadas (JACOBS, 2004; KIRKPATRICK, PARKER, ZHANG, 2004, 2003).

Este trabalho, originado de um dos projetos realizados no âmbito do PRO-REG, tem como objetivo principal analisar como variáveis políticas e organizacionais influenciam o processo de difusão da AIR no contexto brasileiro, integrando as duas perspectivas teóricas acima mencionadas. A pesquisa realizada buscou diagnosticar as capacidades organizacionais existentes no governo federal, assim como dimensões de natureza política que possam influenciar a forma como a AIR pode se difundir no Brasil. O estudo também buscou diferenciar a AIR como instrumento de melhoria regulatória dos modelos organizacionais necessários para sua adoção, partindo do pressuposto de que atores importantes do marco regulatório brasileiro reagirão de maneira diferente a essas duas dimensões.

Para tanto, o artigo está estruturado em cinco seções. A primeira apresenta o referencial teórico, no decorrer do qual se discutem os principais conceitos relacionados com a AIR, as teorias que explicam sua difusão no contexto internacional e algumas especificidades do contexto brasileiro que possam influenciar a adoção da AIR no Brasil. Em seguida, descreve-se a metodologia utilizada e discutem-se os resultados da pesquisa. Especificamente, buscaram-se avaliar a familiaridade com o instrumento de AIR, as capacidades organizacionais existentes no governo federal, o contexto burocrático, o processo de políticas públicas e a posição dos principais atores do marco regulatório brasileiro.

\section{REFERENCIAL TEÓRICO}

\section{AIR - principais conceitos}

A AIR é um dos instrumentos disponíveis para melhorar a qualidade da regulação e consiste na análise e avaliação dos possíveis benefícios, custos e impactos de regulamentações novas ou já existentes (OCDE, 2008b). Para Kirkpatrick e Parker (2004), AIR pode ser definida como um método capaz de ajudar no desenho, na implementação e no monitoramento de melhorias dos sistemas regulatórios, oferecendo uma metodologia de avaliação das consequências de regulamentações novas e já existentes. Em boa parte das experiências internacionais, predomina o uso da AIR pelo Poder Executivo, que pode utilizar o instrumento para acompanhar novas propostas de lei ou determinar que agências o utilizem na elaboração ou modificação das normas infrarregulatórias.

Em termos práticos, AIR começa com a identificação e análise do problema e dos objetivos que se buscam alcançar por meio de determinada política regulatória e continua com a avaliação dos custos e benefícios dos possíveis processos para a sua implementação, optando 
pela alternativa que oferece o maior benefício público (OCDE, 2008b). Uma AIR satisfatória deve seguir esses aspectos centrais (EU, 2004, p. 11):

a) Definição adequada do problema e identificação dos objetivos da política regulatória, de modo a evitar ambiguidades e contradições (apresentando os resultados esperados em termos quantitativos e hierarquizando os objetivos, sempre que possivel);

b) Início da avaliação quando ainda existem várias escolhas; consideração de múltiplas opções;

c) Coleta de informação, preferencialmente via consultas públicas - e avaliação dos dados, com base numa escolha explícita de critérios, procedimentos e técnicas a serem utilizados;

d) Avaliação ex-ante de impactos de cada opção, por meio de métodos explícitos e consistentemente utilizados; descrição e, na grande maioria dos casos, quantificação dos efeitos; seleção explícita dos tipos de efeitos a serem considerados;

e) Apresentação e publicidade dos resultados da AIR numa forma transparente.

Entretanto, para Radaelli (2005), estes são elementos de um modelo ideal de AIR, baseado nos pressupostos de um processo de políticas públicas de natureza racional, distante da realidade da maioria dos países em desenvolvimento.

Organismos internacionais que recomendam a adoção do instrumento destacam, entre os benefícios da AIR, o fortalecimento da governança regulatória, a melhoria da competitividade do país via um ambiente regulatório mais sólido, o apoio à tomada de decisão no processo de políticas públicas, assim como a difusão de uma cultura e linguagem comum em termos de regulação (OCDE, 2008b; EU, 2004). Essa perspectiva é compartilhada também por pesquisas científicas, de acordo com as quais a AIR pode contribuir para as duas dimensões de um "bom" sistema regulatório: a) os instrumentos ou formas legais selecionados para alcançar os objetivos desejados; e b) os procedimentos ou os processos pelos quais esses instrumentos são formulados e aplicados. A primeira contribuição da AIR referese aos resultados/objetivos alcançados em termos de desenvolvimento econômico, social, ambiental e sustentável, enquanto a contribuição processual é medida pelos princípios da boa governança, uma vez que o instrumento promove a consistência, a accountability e a transparência do processo na tomada de decisão Kirkpatrick, Parker e Zhang (2003).

Entretanto, existem também críticas ao uso da AIR, especialmente dirigidas à análise custo-benefício (ACB) que serve de base ao instrumento. Para Shapiro (2010), no contexto norte-americano, os apoiadores de maior regulamentação criticam a ACB pelo papel desempenhado na redução das proteções em áreas como meio ambiente, saúde ou segurança, enquanto os oponentes à maior regulamentação incentivam o maior uso da técnica, citando o custo que as regulamentações impõem para os negócios. A crítica de natureza mais acadêmica também persiste em áreas como meio ambiente ou saúde, onde a AIR é criticada pelos vieses da ACB ou considerada imoral, por atribuir valor monetário a vidas humanas ou questões ambientais (HEINZERLING e ACKERMAN, 2007). Outros trabalhos defendem que decisões sobre saúde, segurança ou meio ambiente devem ser fundamentadas em valores democráticos e escolhidas com base em julgamentos morais, em vez de ACBs (HEINZERLING e ACKERMAN, 2007; HEINZERLING, ACKERMAN, MASSEY, 2004). O fato é que a ACB vem se consolidando como um instrumento de tomada de decisão regulatória, independentemente das críticas que vem acumulando ao longo das décadas, e se difunde em vários países do mundo (SHAPIRO, 2010).

\section{O processo de dif́usão da AIR}

Originada no contexto norte-americano, o recurso à AIR vem se espalhando internacionalmente. Nos EUA, a AIR institui-se com ordem executiva do presidente Reagan, que demandava às agências federais a utilização do instrumento para novas regulamentações. O recurso à AIR é obrigatório para agências da administração direta, como United States Environmental Protection Agency (EPA). No entanto, agências regulatórias de natureza independente podem aderir à AIR voluntariamente. A União Europeia adotou o instrumento em 2002, apenas para iniciativas relevantes de políticas públicas. No que tange à avaliação da experiência nesses países, estudos têm revelado que a qualidade das AIRs preparadas pela Comissão europeia é menor quando comparada com as AIRs norte-americanas, embora uma pesquisa recente tenha verificado que não existem diferenças substanciais de qualidade quando as AIRs são preparadas para custos acima de U\$ 100 milhões nos dois países (CECOT e outros, 2008). A AIR difundiu-se e atualmente é utilizada em países como Canadá, Austrália, México, Reino Unido, Dinamarca e Holanda, com crescente adesão de outros países do mundo, como consequência de recomendações recentes de organismos internacionais (EU, 2004). De acordo com Rodrigo (2005), até o final de 2000, 14 países-membros da OCDE tinham adotado programas abrangentes de aplicação da AIR, 
enquanto seis outros usavam o instrumento para algumas regulamentações.

A lógica que permeia o processo de adoção da AIR baseia-se num processo racional de tomada de decisão, melhoria de resultados econômicos e fortalecimento de governança democrática. A popularidade crescente da AIR pode ser compreendida pela atratividade desses benefícios esperados, especialmente por parte de governos envolvidos em reformas de melhoria regulatória (OCDE, 2008b). Naturalmente, mecanismos como comunicação transnacional de modelos de políticas públicas (especialmente, promovidas por organismos internacionais como OCDE, no caso da AIR) e pressões de natureza coercitiva, normativa e mimética, originadas de ideias e discursos novos, influenciam a difusão da AIR internacionalmente (RADAELLI, 2005).

Entretanto, esses fatores não explicam a falta da convergência na forma como a AIR é implementada em diversos contextos nacionais. Dependendo desses contextos, a AIR existe apenas formalmente ou está relacionada com práticas diferentes sob a mesma denominação (RADAELLI, 2005; RADAELLI e FRANCESCO, 2007).

Duas perspectivas teóricas buscam compreender as variáveis contextuais que influenciam o processo de difusão da AIR: a) a perspectiva política enfatiza o papel das variáveis políticas presentes no contexto doméstico onde a AIR é adotada (RADAELLI, 2005, 2007, 2009); e b) a perspectiva organizacional, dominante no estudo da difusão da AIR em países em desenvolvimento, foca em capacidades organizacionais ou medidas procedimentais para compreender a forma como a AIR é difundida (JACOBS, 2004; KIRKPATRICK, PARKER, ZHANG, 2004, 2003). Essa última perspectiva predomina também nos relatórios dos organismos internacionais (OCDE, 2008b; EU, 2004).

De acordo com Radaelli (2005), a difusão sem convergência da AIR pode ser compreendida pelo papel das variáveis políticas operantes no contexto doméstico, particularmente: a) especificidades do contexto burocrático, tais como concentração versus delegação de poderes regulatórios para agências ou orientação profissional da burocracia das agências etc.; b) processo de políticas públicas, que especifica se a AIR é próxima de um modelo "ideal" de políticas públicas, de natureza harmoniosa, com atores unitários e poucos gaps de informação, ou se a AIR aproxima-se a um modelo "ideal" do tipo garbage-can, em que os problemas são constantemente reformulados por diversos atores políticos, soluções modificam-se frequentemente e as competências das diferentes unidades são pouco claras; c) atores envolvidos com AIR que são relevantes para o processo de formu- lação de políticas públicas, dependendo dos diversos contextos institucionais; e d) conceitos de legitimidade regulatória que predominam em dado contexto, dependendo do grau de envolvimento de poucos ou muitos atores nos processos de AIR.

Outros estudos comparativos relativos ao processo de difusão da AIR corroboram a tese de Radaelli (2005), mas atribuem essa divergência na difusão do instrumento a variáveis de ordem organizacional ou procedimental, tais como:

a) natureza processual: obrigatoriedade do ato normativo, processo de aprendizagem, justa "dosagem" da abrangência de aplicação do instrumento; ou

b) natureza organizacional, entre as quais se destacam o adequado desenho organizacional para implementar a AIR, as características do staff do órgão responsável para implementar a AIR, o recrutamento de especialistas ou treinamento de RH necessários para aplicar o instrumento, a existência de banco de dados quantitativos para viabilizar a análise de alternativas, entre outros (RODRIGO, 2005; EU, 2004).

Enquanto as características processuais vêm sendo aprimoradas em vários países do mundo (ex.: EUA, Canadá, Reino Unido ou Austrália estão revisando os métodos e escopo da AIR, melhorando os processos de avaliação do risco ou as metodologias de coleta de dados), a experiência comparativa aponta que não existe um único melhor modelo de implementação da AIR. O mesmo pode ser afirmado com relação aos desenhos organizacionais e institucionais, que diferem de um país para o outro. O fato é que os desafios institucionais e organizacionais são presentes em qualquer processo de introdução da AIR, especialmente em países em desenvolvimento, pela falta de apoio político ou percepção de custos excessivos de adoção do instrumento (OCDE, 2008b).

O uso, ou o potencial uso, da AIR em países em desenvolvimento tem sido pouco analisado, mas os estudos existentes também corroboram a tese de "difusão sem convergência" da AIR. Os principais estudos sobre adoção da AIR nesses contextos relacionam-se com as experiências da Coreia e do México (países-membros da OCDE) e identificam sérios problemas de adoção do instrumento. Estudos da OCDE sobre a experiência coreana apontam um gap de implementação significante e um baixo nível de sofisticação da AIR na prática, como consequência da falta de capacidades técnicas dos representantes do governo, enquanto as falhas da experiência mexicana são atribuídas à baixa qualidade das 
informações e dos dados necessários, que impossibilita análises quantitativas das propostas regulatórias. Logo, o medo de incentivar a produção de análises quantitativas distorcidas, contribuindo ainda mais para a baixa qualidade dos dados, faz com que as autoridades regulatórias não sejam demandadas a utilizar a AIR (KIRKPATRICK, PARKER, ZHANG, 2003).

Estudo de Kirkpatrick, Parker e Zhang (2004) para analisar a adoção da AIR em países em desenvolvimento ou transição (incluindo também o Brasil) revela outro obstáculo à sua adoção: a ambiguidade conceitual do termo. Segundo os autores, existe alguma compreensão sobre AIR e seus princípios, mas essa compreensão não parece ser largamente difundida, com variações presentes entre as diversas agências e os departamentos governamentais dentro do mesmo país. O uso da AIR é um requerimento formal em 10 dos 40 países pesquisados (especificamente, Coreia, Filipinas, Tanzânia, Jamaica, México, Albânia, Lituânia e Romênia), e 30, dos 40 países, afirmam que a AIR é utilizada, de alguma forma, mesmo não sendo um requerimento legal. É interessante também observar que boa parte dos respondentes era formada por reguladores de indústrias em rede (energia elétrica e telecomunicações), embora também tenham sido incluídos na amostra outros departamentos governamentais (o que também aproxima essa pesquisa da apresentada aqui). Especificamente na América Latina, seis países responderam que fazem algum uso da AIR e três outros negaram seu uso, uma resposta relativamente baixa, considerando que os sistemas regulatórios foram desenvolvidos há algum tempo nessa região.

\section{Especificidades do contexto regulatório brasileiro}

O contexto regulatório brasileiro é caracterizado por algumas especificidades que podem influenciar o processo de difusão da AIR. Destaca-se, primeiramente, uma predominância da concepção econômica da regulação. De fato, a regulação está relacionada com a mudança no papel do Estado decorrente dos processos de desregulamentação e privatização dos anos 1990, uma reforma com consequências econômicas, políticas e institucionais. A regulação foi definida em termos de instrumentos econômicos que coíbem os comportamentos anticompetitivos das empresas. Os primeiros anos da reforma centraram-se na criação de entidades regulatórias independentes em setores de serviços públicos como eletricidade ou telecomunicações, abordando, principalmente, o formato organizacional e o papel institucional desses órgãos. Entretanto, outros entes da administração pública almejavam a independência dos entes regulatórios, como uma forma de obter maior autonomia de gestão. Assim, no período de 1999 a 2002, o formato organizacional de agência independente difundiu-se em setores como água, saúde suplementar, vigilância sanitária etc. Embora tenham objetivos diferentes, as agências brasileiras são caracterizadas por um alto grau de isomorfismo organizacional. Formalmente, estas dependem dos ministérios, os quais são responsáveis por formular políticas regulatórias. No entanto, ao longo dos anos, o corpo técnico das agências, o conhecimento especializado desses órgãos e o esvaziamento dos ministérios contribuíram para concentrar o processo de formulação e implementação de políticas regulatórias nas agências, abrindo espaço para questionamentos do modelo (MARTINS, 2004; MELO, 2002; PECI, 2007).

É importante destacar que o fortalecimento dos entes regulatórios brasileiros seguiu uma tendência histórica. De fato, o núcleo forte da burocracia brasileira sempre foi localizado em autarquias, fundações ou empresas públicas, não em ministérios. A reforma regulatória dos anos 1990 transferiu boa parte desse núcleo para os entes regulatórios independentes. Consequentemente, as agências regulatórias concentram também o poder de regulamentação, compreendido como o poder normativo de elaboração ou revisão de normas infrarregulatórias, enfraquecendo mais esse papel dos ministérios (FARIA e RIBEIRO, 2002).

Embora uma série de medidas de consolidação do marco regulatório ainda esteja em curso (destacando aqui o Projeto-Lei das Agências Reguladoras), os fatores acima analisados servem para contextualizar as peculiaridades do cenário brasileiro que poderão influenciar a difusão da AIR.

A OCDE recomenda a adoção da AIR visando à melhoria da qualidade regulatória, com base em uma perspectiva de "governo como um todo", que privilegia a definição mais ampla da regulação, além da dimensão econômica, e aproximando-se da regulamentação como poder normativo. Por isso, além dos entes regulatórios independentes, o relatório recomenda que a AIR seja adotada por todos os órgãos com poder de regulamentação (OCDE, 2008a).

Considerando esse contexto do marco regulatório brasileiro, esta pesquisa busca compreender como os fatores contextuais influenciarão o processo de difusão da AIR no Brasil, integrando as perspectivas política e organizacional sobre a adoção do instrumento em países em desenvolvimento. Especificamente, este estudo baseou-se nas seguintes categorias de análise: 
a) Familiaridade do conceito: a AIR está sendo introduzida no Brasil, e estudos demonstram que, nos países em desenvolvimento, pode prevalecer certa ambiguidade conceitual sobre o instrumento entre os principais stakeholders (Kirkpatrick, Parker, Zhang, 2004). Os próprios conceitos de regulação versus regulamentação são controversos, considerando que prevalece, no país, uma perspectiva econômica da regulação.

b) Capacidades organizacionais: capacidades existentes nas entidades com poder de regulamentação, em termos organizacionais, podem influenciar positivamente ou negativamente o processo de difusão da AIR.

c) Contexto burocrático: a concentração da autoridade regulatória apenas em alguns órgãos ou sua descentralização para um número grande de agências independentes, como no caso brasileiro, pode influenciar a implementação da AIR e motivar os representantes políticos a exercer controle sobre o processo de decisão das agências independentes.

d) Processo de políticas públicas: peculiaridades do processo de políticas públicas, como alta fragmentação e falta de coordenação entre diversas unidades e agências governamentais, disparidades em termos de modelos organizacionais ou instrumentos regulatórios - aproximando-se de um modelo garbage-can - podem também influenciar o processo de difusão da AIR , especificamente, a percepção acerca do instrumento e a motivação para sua adoção.

e) Atores centrais nas políticas regulatórias: considerando a fase introdutória da AIR no contexto brasileiro, representantes das agências reguladoras, líderes políticos e representantes dos ministérios destacam-se entre os atores principais que podem influenciar a adoção do instrumento.

A legitimidade, um importante fator contextual de natureza política, não será analisada neste trabalho, considerando que o estágio introdutório da AIR no Brasil não permite avaliar o número de atores que serão incluídos ou excluídos do processo.

\section{METODOLOGIA DO TRABALHO}

Em termos metodológicos, o trabalho proposto foi desenvolvido com base nas seguintes linhas:

a) Benchmarking da experiência internacional: realizado com o objetivo de identificar estruturas organizacionais adotadas por outros países com experiência consolidada (ou em vias de consolidação) no uso da AIR, procurando destacar os modelos que possam ser adaptados ao contexto brasileiro.

Especificamente, foram analisados o caso norteamericano, pioneiro na adoção da AIR, o caso da União Europeia, caracterizado por uma relativa complexidade institucional, próxima ao contexto brasileiro, o caso do Reino Unido, considerando o estágio avançado de desenvolvimento do instrumento, e o caso do México, considerando a proximidade cultural com o contexto brasileiro.

Os dados foram coletados via análise documental e bibliográfica, mas também comunicações diretas foram estabelecidas com órgãos supervisores da qualidade regulatória, no caso de surgimento de dúvidas (como no caso do Better Regulation Executive, do Reino Unido).

b) Pesquisa de campo em agências reguladoras e outros representantes de públicos-alvo importantes ao contexto brasileiro: realizada com o objetivo de avaliar a percepção acerca da potencialidade, assim como possíveis obstáculos à adoção da AIR no cenário federal brasileiro. Concretamente, foram entrevistados 15 representantes da alta direção dessas agências reguladoras, assim como ex-presidentes de agências reguladoras, de acordo com o quadro que segue na página seguinte.

Paralelamente, foram entrevistados atores-chave do processo regulatório brasileiro, visando inserir os modelos propostos numa perspectiva maior institucional, que considere o governo como um todo. Concretamente, foram realizadas 13 entrevistas com atoreschave do ambiente regulatório: dois representantes do Ministério de Minas e Energia (órgão formulador de políticas públicas); dois do Tribunal de Contas da União (especificamente, do Sefid, órgão responsável pelo controle da regulação, com larga experiência em avaliações ex-ante e informação transversal acerca das agências reguladoras de infraestrutura); representantes do Poder Legislativo com atuação na área de regulação (quatro membros do Gabinete do Senador Tasso Jereissati), representantes da sociedade civil organizada (o presidente e três diretores da Associação Brasileira de Agências de Regulação - ABAR) e um representante da OCDE.

A pesquisa desenvolvida foi de natureza qualitativa e os meios privilegiados de coleta de dados fo- 


\section{Quadro 1 - Lista dos entrevistados em órgãos reguladores}

Agência reguladora

Anvisa (Agência Nacional de Vigilância Sanitária)

ANS (Agência Nacional de Saúde Suplementar)

Aneel (Agência Nacional de Energia Elétrica)

ANP (Agência Nacional de Petróleo)

Ancine (Agência Nacional de Cinema)

Aneel/ANA (Agência Nacional das Águas)

Anatel (Agência Nacional de Telecomunicações)
Entrevistados

Presidente, diretor, dois assessores da Presidência

Presidente

Três diretores da Diretoria Colegiada

Chefe de gabinete, dois superintendentes

Chefe de gabinete, uma assessora

Ex-presidente

Ex-presidente ram pesquisas bibliográfica, documental e entrevistas semiestruturadas em torno das categorias analíticas acima destacadas: a) familiaridade com o conceito da AIR; b) diagnóstico das capacidades organizacionais já existentes no governo federal, levantadas com base nas principais dimensões do modelo ideal da AIR; c) peculiaridades do contexto burocrático que podem influenciar a difusão da AIR; d) peculiaridades do processo de políticas públicas que podem influenciar a difusão da AIR; e, por fim, e) papel dos atores centrais na adoção da AIR, focando na percepção acerca da AIR e na motivação que pode levar à adoção do instrumento.

O conteúdo das entrevistas adaptou-se às características particulares dos diferentes públicos-alvo, buscando observar as principais categorias analíticas. As entrevistas tiveram uma duração modal de uma hora, mas houve casos em que se estenderam por mais tempo. As entrevistas foram transcritas e os dados foram tratados via análise de conteúdo com grade mista (VERGARA, 2006), que permitiu a codificação das frases e parágrafos transcritos de acordo com as categorias conceituais, mas também a modificação de algumas categorias, quando fosse o caso. Dessa forma, ao longo do trabalho, surgiu a necessidade de diferenciar a percepção da AIR enquanto instrumento de controle, da percepção acerca dos modelos organizacionais necessários para implementar o instrumento. Os dados obtidos por meio de entrevistas foram confrontados com a literatura sobre as agências regulatórias e com as categorias centrais do trabalho, permitindo refletir acerca das principais conclusões da pesquisa. Vale destacar que a participação, ao longo do projeto, em vários encontros de trabalho sobre o tema, como o Seminário Internacional de Avaliação do Impacto Regulatório e Reuniões de Trabalho, realizados pelo PRO-REG, serviu como importante troca de opiniões, coleta de dados e sua validação.

\section{APRESENTAÇÃO E DISCUSSÃO DOS RESULTADOS}

\section{Familiaridade com o instrumento de AIR}

Os resultados da pesquisa de campo realizada parecem confirmar os achados do estudo realizado por Kirkpatrick, Parker e Zhang (2004), voltado para a AIR em países de economias em desenvolvimento ou transição, onde o Brasil também foi incluído. De fato, essa pesquisa também revela que a AIR é um instrumento desconhecido por boa parte dos entrevistados, sejam eles órgãos reguladores, sejam públicos diretamente ou indiretamente envolvidos no processo de regulamentação. No entanto, após a definição do termo, os entrevistados reconhecem que práticas que definem a AIR são parcialmente adotadas, embora não de maneira sistematizada, no exercício da atividade de regulamentação.

Como se destaca ao longo da entrevista com o presidente da ANS, dependendo do tipo da resolução elaborada pela agência, simulações "jogadas, por exemplo, num conjunto de análises de impactos das garantias sobre o faturamento das empresas" ou ambientes públicos de discussão, no caso da ANS, consultas públicas e câmaras técnicas, onde "sentam representantes de operadoras, de órgãos de defesa do consumidor, de 
prestadores de serviços, sejam pessoas físicas ou pessoas jurídicas, médicos, hospitais, odontólogos, entidades que representam o usuário, tanto do ponto de vista sindical, patronal, dos trabalhadores e órgãos do governo [...] se reúnem no momento de discutir uma resolução, do ponto de vista técnico" são práticas correntes no âmbito da agência. Essas práticas caracterizam o modelo "ideal" de AIR e já se encontram presentes no dia a dia de gestão dos órgãos reguladores brasileiros, como também será discutido a seguir.

\section{Diagnóstico das capacidades organizacionais existentes}

A transferência bem-sucedida da AIR num novo contexto nacional demanda a avaliação das capacidades organizacionais e humanas já existentes nos órgãos responsáveis pela produção normativa objeto da avaliação. Boa parte da pesquisa de campo dedicou-se ao levantamento dessas capacidades, especialmente nos órgãos reguladores independentes, que assumem significativa parcela da produção normativa no contexto brasileiro.

De modo geral, é possível afirmar que uma grande parcela do corpo dirigente das agências responde positivamente ao desafio da adoção sistemática da AIR no Brasil. A razão principal desse apoio reside no fato de que muitas agências reguladoras brasileiras já incorporaram alguns dos aspectos centrais do modelo ideal de AIR:

- Detêm e fazem uso de sistemas de informação e bancos de dados consolidados, com informações abrangentes sobre os setores regulados e seus principais stakeholders;

- Incorporam instrumentos de transparência e comunicação com os públicos-alvo (como consulta pública, audiência pública, câmara consultiva etc.), enquanto os ministérios fazem uso eventual deles. Agências como Aneel podem potencializar as boas práticas no uso da consulta e audiência pública;

- Primam por um processo racional de tomada de decisão, baseado na elaboração de estudos sofisticados, de natureza quantitativa, que apoiam o processo de tomada de decisão regulatória;

- Elaboram agenda regulatória (especificam prioridades de regulação, necessárias para compreender quais os problemas e objetivos da regulamentação).

A disponibilidade das informações fidedignas é um dos principais pré-requisitos para uma boa AIR. As agências reguladoras brasileiras, ao longo dessa década de estruturação, foram responsáveis pela captura e siste- matização de informações relevantes referentes aos seus mercados de atuação (no caso da Anvisa, de natureza multissetorial). Bancos de dados sofisticados existem em quase todas as agências pesquisadas e podem ser utilizados no processo de elaboração da AIR. A diretoria da Aneel afirma que, atualmente, o órgão teria mais dados e informações que permitiriam uma boa análise de impacto do que o respectivo ministério, enquanto o presidente da ANS destaca: "nós temos um conjunto de informações econômicas, assistenciais, hoje é bastante comum; nós temos três sistemas que acompanham sistematicamente as pessoas [...] e temos vários sistemas [... [ digamos, acessórios".

No entanto, a capacidade informacional não é igual em todos os órgãos pesquisados. Alguns, como a Anvisa, destacam que a complexidade multissetorial do órgão dificulta a construção de bons indicadores a serem utilizados na AIR.

Com relação aos instrumentos de transparência, boa parte das agências reguladoras tem avançado no recurso ao processo de consulta pública, adotado pela maioria dos órgãos. Segue trecho da entrevista com os diretores da Aneel:

"[...] Aneel usa extensivamente - e, aliás, por conta de obrigação legal - o mecanismo de audiência pública, então, toda vez que houver aceitação de direito, a lei estabelece que a Aneel deve ouvir as partes; [...] não passa uma semana sem que nós não estejamos submetendo alguma proposta à audiência pública [...] de posse das contribuições recebidas, é obrigatória a elaboração de um relatório detalhado que faça análise das contribuições".

(Pergunta): e (as contribuições) são levadas em consideração na tomada de decisão?

(1): são, são parte essencial, e são analisadas criteriosamente.

Várias das agências pesquisadas também primam por um processo racional de tomada de decisão. De fato, a produção normativa dos órgãos (que pode assumir a natureza de resolução, instrução normativa etc.), de modo geral, baseia-se em estudos complexos, boa parte de natureza quantitativa, que recorrem às informações presentes nos bancos de dados das agências e ao processo de consulta pública.

Quando indagadas sobre o recurso a análises racionais, de natureza quantitativa, no processo de tomada de decisão, vários órgãos responderam positivamente:

Aneel: "Eu acho que a maioria [das regulamentações]; eu acho assim, não dá pra dizer 90\%, mas a maioria; [...] pelo menos os regulamentos mais importantes sempre são feitos, na minha visão, com base nesse tipo de análise". 
Por fim, a AIR pode ser redefinida como um processo de gestão regulatória por resultados, onde a definição dos objetivos de uma agenda regulatória torna-se um prérequisito para adoção bem-sucedida do instrumento. Essa necessidade sente-se, na prática da atuação dos órgãos reguladores, especialmente, considerando o contexto de desarticulação da formulação com a implementação de políticas públicas existentes no país.

Algumas agências já partiram para um processo de elaboração da agenda regulatória, responsável por especificar prioridades da regulamentação num determinado espaço de tempo. No entanto, a necessidade de lidar com a formulação de objetivos regulatórios surge como problemática no contexto de pouco alinhamento dos ciclos das políticas regulatórias, de enfraquecimento da capacidade de elaboração de políticas no nível dos ministérios, e pode revelar-se um obstáculo à difusão da AIR no Brasil.

\section{Contexto burocrático}

O contexto burocrático brasileiro é caracterizado pela delegação dos poderes regulatórios para um considerável número de agências regulatórias de natureza independente, similarmente ao contexto norte-americano. As agências são majoritariamente setoriais, orientadas por políticas públicas de natureza especializada (com exceção da Anvisa, uma agência multissetorial e uma das primeiras a adotar o projeto piloto da AIR). A maioria das agências conta com profissionais qualificados (principalmente com expertise setorial, como engenheiros na Anatel, médicos e economistas na ANS, diferentemente dos EUA, onde predominam economistas) e seus quadros são treinados em questões regulatórias.

No entanto, diferentemente do contexto norte-americano, a independência das agências é um conceito novo no quadro institucional brasileiro, tradicionalmente dominado pelo Executivo em detrimento de outros poderes. A orientação pela eficiência continua a ser um objetivo secundário num contexto com cultura legalística predominante. Existem muitas diferenças entre as agências independentes, em termos de grau de autonomia e modus operandi. De acordo com um dos entrevistados, representando a OCDE:

"No Brasil, os marcos regulatórios não são claros e diferem dependendo da instituição. Existem inúmeras instituições, como autarquias, agências ou ministérios com poder regulatório, mas não é evidente como esse poder é exercido, na prática".

Nesse contexto:

"As agências regulatórias foram selecionadas como projeto piloto para introduzir a AIR por razões instru- mentais, considerando que: não existem capacidades organizacionais nos ministérios em termos de recursos humanos; é mais fácil começar a AIR com uma questão técnica do que com políticas públicas, uma vez que falta tradição nessa perspectiva; é mais fácil concentrar as análises de AIR dentro do Executivo, evitando o Legislativo, de forma a ultrapassar problemas relacionados com a falta de familiaridade e com o engajamento com o instrumento".

Entretanto, a instrumentalidade dessa escolha pode influenciar a falta de convergência em práticas futuras de AIR, especialmente quando se consideram as peculiaridades institucionais das "novas" agências regulatórias independentes, que serão exploradas a seguir.

\section{Processo de políticas públicas}

A diversidade do contexto burocrático brasileiro também pode ser relacionada com a dinâmica das políticas públicas. De fato, o Brasil assemelha-se a países como Alemanha ou Itália, onde o processo regulatório é altamente fragmentado, com múltiplos pontos de contato entre a política e a administração, assim como entre diferentes lógicas e critérios (RADAELLI, 2005). Estudos anteriores (FARIA e RIBEIRO, 2002; MARTINS, 2004; OCDE, 2008a; PECI, 2007; SANTOS, 2009) têm diagnosticado problemas no processo de políticas regulatórias, que também foram corroborados pelos entrevistados no decorrer da pesquisa de campo e estão sintetizados a seguir:

a) fragmentação de instituições e do marco regulatório, resultando na ausência de um "sistema" coerente regulatório;

b) fraca vinculação com o processo de formulação de políticas públicas, especialmente, devido à falta de atuação dos órgãos responsáveis nessa fase do processo;

c) confusão de atribuições referentes às agências reguladoras vis-à-vis ministérios supervisores;

d) relativa complexidade das instituições regulatórias, em comparação com os modelos internacionais, especialmente em relação à: a) multiplicidade de modelos organizacionais e institucionais, que diferem de um setor para outro e dificultam uma abordagem intersetorial; e b) multiplicidade de instrumentos regulatórios que dificultam o intercâmbio de experiências e ganhos de aprendizagem;

e) baixa cultura de accontability e uso precário de instrumentos que aumentam a transparência.

Essa variabilidade do processo regulatório pode influenciar negativamente a adoção da AIR no Brasil, 
especialmente quando se considera que instrumentos como AIR são baseados num ideal racional de políticas públicas, com atores unitários e baixo gap informacional, um modelo distante do processo fragmentado acima descrito, mais próximo ao garbage-can (RADAELLI, 2005).

O processo fragmentado e diversificado de políticas regulatórias, alinhado com a cultura legalística, pode influenciar uma difusão sem convergência da AIR no Brasil. De qualquer forma, também se pode esperar uma alta variabilidade no nível de agências na forma como a AIR é adotada e utilizada. Agências mais consolidadas podem utilizar o instrumento para subsidiar um processo mais racional e empírico de tomada de decisão.

\section{Atores centrais}

As lógicas, as preferências e os critérios dos atores envolvidos na formulação de políticas públicas dependem dos diversos contextos institucionais onde estes estão inseridos e ajudam a compreender as diferenças encontradas na adoção da AIR, seja em termos de quem está no comando desse instrumento de avaliação, seja em termos da forma como a qualidade da AIR é percebida (RADAELLI, 2005). Na fase introdutória da AIR no contexto brasileiro, quando seus objetivos e conteúdo ainda não estão definidos (e ainda não estão especificados os atores que serão incluídos/excluídos no processo), é importante analisar o papel de dois atores centrais: representantes do Poder Executivo e das agências reguladoras.

Com relação ao Executivo, incentivador da adoção da AIR, é importante diferenciar dois subgrupos de atores: ministérios intersetoriais, como a Casa Civil da Presidência da República, responsável pela coordenação da AIR no país, e ministérios especializados, diretamente relacionados com as agências reguladoras.

O papel central desempenhado pela Casa Civil na adoção da AIR pode ser compreendido à luz da relação com as agências independentes. De fato, embora o Poder Executivo tenha dominado, historicamente, o palco político brasileiro, o governo Lula confrontou-se com o desafio imposto pela independência dos entes regulatórios, e a AIR pode ser um instrumento interessante de controle político da burocracia regulatória (RADAELLI e FRANCESCO, 2007; RADAELLI, 2005).

Por outro lado, ministérios que trabalham diretamente com as agências são considerados fracos em termos de capacidade organizacional e de formulação de políticas públicas, conforme sintetizado pelo Presidente da ANS:
"Aí você tem um grave problema nisso, é o esvaziamento dos ministérios supervisores do ponto de vista da competência do assunto em discussão; então, por exemplo, a discussão da ANS com o ministério supervisor, com o Ministério da Saúde, sobre esse assunto é quase um diálogo de surdos; [...] as agências ficam autônomas pelo [...] impossibilidade de o seu ministério supervisor definir metas, definir diretrizes, definir políticas".

A AIR pode tornar-se um instrumento interessante de recuperação da capacidade de formulação de políticas regulatórias por parte dos ministérios, fortalecendo o controle que estes possam exercer nas decisões atualmente concentradas nas agências independentes.

Por outro lado, a percepção da burocracia das agências reguladoras com relação à AIR é ambivalente. As agências olham de maneira positiva a AIR enquanto instrumento de melhoria regulatória, mas resistem aos modelos organizacionais necessários para sua implementação, tais como a criação de um órgão de supervisão da qualidade regulatória.

AIR como um instrumento de melhoria regulatória é percebido positivamente pela maioria dos entrevistados que representam as agências reguladoras e é apresentado como principal motivação para sua futura adoção. Atualmente, existem poucos órgãos de nível federal com alguma experiência formalizada e sistematizada de AIR.

O projeto piloto adotado pela Anvisa destaca-se nesse contexto e foi objeto de análise mais aprofundada durante a pesquisa de campo. A AIR parece ser uma consequência natural do processo de consolidação do marco regulatório brasileiro após o processo de reestruturação econômica e social dos anos 1990. Conforme o seu presidente, a Anvisa, "em dez anos de existência, editou 900 resoluções", considerando que "o marco regulatório na área sanitária no Brasil ou era muito ruim ou estava muito defasado". "Por conta disso, nós precisávamos ordenar, porque efetivamente a profusão de regras necessárias é muito grande". Dessa forma, a AIR faz parte de uma tentativa de melhoria do processo de regulamentação, uma necessidade que surge naturalmente como consequência de aperfeiçoamento do marco regulatório no Brasil.

Outras agências, como a Ancine, destacam o potencial da AIR na simplificação e racionalização da produção normativa do órgão. Os órgãos pesquisados revelam que estão iniciando os debates internos acerca da AIR e destacam também o papel do PRO-REG na divulgação e conscientização acerca da importância desse instrumento. É fundamental observar, no entanto, que essa sensibilização e conscientização, de modo geral, foi observada com mais força no segun- 
do nível decisório das agências - as que participam diretamente das reuniões do PRO-REG - e menos na alta direção (com exceção da Anvisa, que conta com apoio total da alta direção e destaca a importância desse apoio nesse processo).

Por outro lado, a pesquisa revelou uma forte resistência aos modelos organizacionais necessários para implementar a AIR, como o órgão supervisor da qualidade regulatória. De fato, no decorrer do benchmarking internacional, observou-se que boa parte dos países pesquisados adota um órgão supervisor da qualidade regulatória vinculado ao Poder Executivo. Uma das etapas da entrevista buscou avaliar a percepção com relação à criação de um órgão supervisor da qualidade regulatória por parte dos órgãos reguladores, assim como de outros públicos-alvo diretamente ou indiretamente relacionados ao processo de regulação.

A pesquisa revela que prevalece uma resistência ao modelo do órgão supervisor da qualidade regulatória, não apenas por parte dos órgãos regulados, mas também pela maioria dos públicos entrevistados. A fonte principal da resistência relaciona-se com a percepção de controle. De fato, independência e supervisão são conceitos conflituosos no caso das agências regulatórias, que buscam fortalecer sua autonomia. Ainda, parece que a confusão dos conceitos regulação versus regulamentação influencia essa percepção. É importante lembrar que a experiência internacional relativa à supervisão da qualidade regulatória não se restringe apenas à atividade dos órgãos reguladores independentes. De modo geral, quando o órgão supervisor da qualidade regulatória existe, sua atividade abrange as AIRs produzidas por órgãos com capacidade de produção normativa, independentemente do seu formato organizacional (administração direta ou indireta, de natureza mais independente). Soma-se, a essa constatação, a diversidade dos formatos institucionais e organizacionais de agências independentes brasileiras, que reúnem desde agências de infraestrutura até agências em áreas como cinema.

Essas ambivalências relacionadas à percepção e à motivação para adoção da AIR podem influenciar uma difusão sem convergência do instrumento no contexto brasileiro. A adoção da AIR pode traduzirse em requerimentos formais (por exemplo, uma nova lei relacionada com a AIR ou a instituição do órgão supervisor) usados para controlar o processo decisório das agências reguladoras, sem, no entanto, influenciar a qualidade das regulamentações novas ou já existentes.

\section{CONCLUSÕES}

Este trabalho avaliou como variáveis contextuais podem influenciar a difusão da AIR no Brasil, integrando as variáveis políticas defendidas por Radaelli $(2005,2009)$ com a perspectiva das capacidades organizacionais que predomina em estudos sobre a adoção do instrumento em países em desenvolvimento.

Em termos teóricos, esta pesquisa corrobora a tese da "difusão sem convergência" da AIR, defendida por Radaelli (2009, 2005). O caso brasileiro de adoção da AIR também revela que os processos de difusão de políticas públicas dependem sempre do contexto local de adoção. Estes adaptam-se, de maneira dinâmica, às diversas combinações de variáveis de natureza política e organizacional - sempre singulares na sua manifestação local. Logo, é de esperar um distanciamento, em maior ou menor grau, de um modelo ideal da AIR, de natureza racional e empiricista, fortemente relacionado com o contexto norte-americano. Esse distanciamento pode influenciar a estratégia de adoção da AIR no Brasil, assim como os resultados diversos, alguns imprevisíveis, advindos da adoção desse instrumento pelo governo federal.

Concretamente, a pesquisa demonstrou, diferentemente dos estudos acerca da AIR em países em desenvolvimento, que existem sólidas capacidades organizacionais no contexto brasileiro e estas podem influenciar positivamente a adoção do instrumento. Entretanto, essas capacidades, embora necessárias, não são suficientes para evitar a falta de convergência em práticas futuras de AIR, uma vez que importantes variáveis políticas também podem influenciar o processo de difusão do instrumento. Essas variáveis dependem do contexto local de adoção e, no caso brasileiro, relacionam-se, principalmente, com as especificidades do contexto burocrático e do processo de políticas públicas.

A crescente difusão internacional da AIR não se traduz imediatamente em familiaridade conceitual e prática com o instrumento, tal como demonstram os resultados dessa pesquisa. De fato, os entrevistados não conhecem formalmente o conceito, embora utilizem frequentemente, no âmbito das agências correspondentes, práticas que caracterizam uma boa AIR, tais como uso constante de sistemas de informação e bancos de dados consolidados com informações sobre os setores regulados e seus principais stakeholders, uso de instrumentos de transparência e comunicação com os seus principais públicos-alvo, recurso a um processo racional de tomada de decisão e elaboração de uma agenda regulatória que especifica as prioridades da política regulatória. 
É interessante observar que o pressuposto de "escassez de capacidades organizacionais em países em desenvolvimento" é compartilhado por pesquisas acadêmicas, assim como por organismos internacionais que apoiam a adoção do instrumento (como no caso da OCDE), e pode influenciar negativamente os diagnósticos acerca da adoção do instrumento, além de levar ao desperdício de valiosos recursos públicos.

A necessidade de diferenciar a AIR enquanto instrumento de qualidade regulatória dos modelos organizacionais necessários para sua implementação é uma recomendação importante que resulta dessa pesquisa. A natureza "neutra" da AIR pode disfarçar a resistência de relevantes atores políticos que, geralmente, se opõem às mudanças políticas que podem decorrer como consequência da instituição de novos modelos organizacionais que centralizam o poder de decisão das políticas regulatórias, como no caso do órgão supervisor da qualidade regulatória. Só a partir desse prisma podem ser interpretadas as percepções ambivalentes relativas à difusão da AIR no Brasil reveladas pela pesquisa. Os órgãos regulatórios independentes buscam manter e consolidar sua autonomia, e a AIR pode ser utilizada para controlar politicamente a burocracia regulatória, especialmente quando seu processo de implementação relaciona-se com mudanças organizacionais que transferem para outros órgãos o foco do processo decisório, atualmente centralizado nas agências independentes.

Consequentemente, a presente reflexão destaca a necessidade de contextualização dos modelos internacionais de supervisão à realidade brasileira e construção de soluções mais customizadas que busquem se adaptar às realidades percebidas e vivenciadas pelos principais atores do contexto regulatório.

\section{REFERÊNCIAS}

ACKERMAN, F; HEINZERLING, L. Priceless: on knowing the price of everything and the value of nothing. New York: The New Press, 2004.

CECOT, C; HAHN, R; RENDA, A; SCHREFLER, L. An evaluation of the quality of impact assessment in the European Union with lessons for the US and the EU. Regulation \& Governance, v.2, n.4, p. 405-424, 2008.
EU (European Union). Italian, Irish and Dutch Presidencies of the Council of the European Union. A comparative analysis of regulatory impact assessment in ten EU countries. Dublin, 2004.

HEINZERLING, L; ACKERMAN, F.. (2007). Wasting Away in Paretoville: A Reply to Cass Sunstein. Harvard Law \& Policy Review, v. 1, n. 2, p. 362-370, 2007.

HEINZERLING, L; ACKERMAN, F; MASSEY, R. Applying CostBenefit to Past Decisions: Was Environmental Protection Ever a Good Idea? Georgetown Public Law Research Paper n. 576161; August. 2004.

FARIA, P, L.C. \& RIBEIRO, S. Regulação e os novos modelos de gestão no Brasil. Revista do Serviço Público, ano. 53, n. 3 , p. 79-93, 2002.

JACOBS, S. Regulatory impact assessment and the economic transition to markets. Public Money and Management, v. 24, n. 5, p. 283-290, 2004.

KIRKPATRICK, C; PARKER, D. Editorial: regulatory impact assessment - an overview. Public Money and Management, v. 24. n. 5. p. 267-270, 2004.

KIRKPATRICK, C; PARKER, D; ZHANG, Y-F. Regulatory impact assessment in developing and transition economies: a survey of current practice. Public Money \& Management, v. 24, n. 5, p. 291-296, 2004.

KIRKPATRICK, C; PARKER, D; ZHANG, Y-F. Regulatory impact assessment in developing and transition economies: a survey of current practice and recommendation for further development. Working Paper. Center on Regulation and Competition. University of Manchester, 2003.

MARTINS, H. F. Reforma do Estado na era FHC: diversidade ou fragmentação da agenda de políticas de gestão pública. Tese de Doutorado, Escola Brasileira de Administração Pública e de Empresas, Fundação Getulio Vargas - Rio de Janeiro, Rio de Janeiro, 2004.

MELO, M. A. As agências reguladoras: gênese, desenho institucional e governança. In: ABRUCIO, F. L.; LOUREIRO, M. R. (Org). O Estado numa era de reformas: os anos FHC. Brasília, parte 2. (Coleção Gestão Pública). 2002.

OCDE. Brasil: fortalecendo a governança regulatória. Relatório sobre reforma regulatória. Brasília: OCDE, 2008a. 
OCDE. Building an institutional framework for regulatory impact analysis: guidance for policy makers. Paris: OECD, 2008b.

PECI, A. Reforma regulatória brasileira dos anos 90 à luz do modelo de Kleber Nascimento. Revista de Administração Contemporânea, v. 11, n. 1, p. 11-30, 2007.

RADAELLI, C. M. Diffusion without convergence: how political context shapes the adoption of regulatory impact assessment. Journal of European Public Policy, v. 12, n. 5 , p. 924-843, 2005.

RADAELLI, C. M. Desperately seeking regulatory impact assessment: diary of a reflective researcher, Evaluation, v. 15, n. 1, p. 31-48, 2009.

RADAELLI, C. M; Francesco, F. D. Regulatory impact assessment, political control and the regulatory state. In: 4TH GENERAL CONFERENCE OF THE EUROPEAN CONSORTIUM FOR POLITICAL RESEARCH, 4, 2007, Pisa. Anais. ECPR, 2007.

RODRIGO, D. Regulatory impact analysis in OECD countries: challenges for developing countries. Paris: OECD, 2005.

SANTOS, L. A. Desafios da governança regulatória no Brasil. Disponível em: www.regulacao.gov.br. Acesso em 07.06.2009.

SHAPIRO, S. The evolution of cost-benefit analysis in U.S. regulatory decision-making. Jerusalem Papers in Regulation and Governance. n. 5, 2010.

VERGARA, S. C. Métodos de pesquisa em administração. 2. ed. São Paulo: Atlas, 2006. 